02

\title{
Влияние молекулярного йода на люминесценцию синглетного кислорода в тетрахлорметане
}

\author{
(C) В.М. Киселев, И.В. Багров, А.М. Стародубцев \\ Государственный оптический институт им. С.И. Вавилова, \\ 199034 Санкт-Петербург, Россия \\ e-mail: kiselevvm21@gmail.com
}

Поступила в редакцию 01.09.2017 г.

Выполнен анализ спектральных свойств люминесценции синглетного кислорода на переходе ${ }^{1} \Delta_{g} \rightarrow{ }^{3} \Sigma_{g}$ с применением красителя бенгальского розового в качестве фотосенсибилизатора. Показано влияние йода в растворе в $\mathrm{CCl}_{4}$ на эффективность генерации синглетного кислорода и на структуру спектра его люминесценции. Выполнено сравнение результатов исследований, полученных с тетрахлорметаном, с другими растворителями.

DOI: $10.21883 /$ OS.2018.02.45523.192-17

\section{Введение}

При сравнении эффективности генерации синглетного кислорода с использованием твердофазного поликристаллического фуллерена $\mathrm{C}_{60}[1]$ с наработкой синглетного кислорода в растворе бенгальского розового в $\mathrm{CCl}_{4}$ нами были замечены характерные особенности в спектре люминесценции синглетного кислорода, наблюдаемой из объема раствора бенгальского розового в $\mathrm{CCl}_{4}$. Наряду с наблюдавшимися ранее более слабыми максимумами люминесценции на длинах волн 1415 и $1588 \mathrm{~nm}$ [1-3] в спектре синглетного кислорода из раствора бенгальского розового в $\mathrm{CCl}_{4}$ появилась еще одна сателлитная линия с $\lambda_{m}=1372 \mathrm{~nm}$, подобная той, которая наблюдалась в растворителях типа $\mathrm{C}_{2} \mathrm{~F}_{4} \mathrm{Br}_{2}$ [2], содержащих тяжелые атомы галогенов. Авторы работы [2] связали эту линию со стоксовой компонентой, индуцированной колебаниями связи $\mathrm{C}-\mathrm{Br}$ растворителя с частотой $513 \mathrm{~cm}^{-1}$ по аналогии с линией на длине волны $1415 \mathrm{~nm}$, индуцированной колебаниями связи $\mathrm{C}-\mathrm{Cl}$ растворителя с частотой $770 \mathrm{~cm}^{-1}$. В тетрахлорметане нет тяжелых атомов галогенов, однако они присутствуют в составе молекулы красителя бенгальского розового в виде атомов йода в соответствии с его формулой $\mathrm{C}_{20} \mathrm{H}_{4} \mathrm{Cl}_{4} \mathrm{I}_{4} \mathrm{O}_{5}$. И, по-видимому, их присутствие в растворе является причиной появления в спектре люминесценции синглетного кислорода еще одной сателлитной линии, близкой по своему положению в спектре к линии, которая наблюдалась в работе [2]. Близость положения этих линий в спектре люминесценции объясняется близостью частот колебаний связей $\mathrm{C}-\mathrm{Br}\left(\sim 550 \mathrm{~cm}^{-1}\right)$ и $\mathrm{C}-\mathrm{I}$ $\left(\sim 500 \mathrm{~cm}^{-1}\right)[4]$.

Исследованиям люминесценции синглетного кислорода в присутствии йода было посвящено немало работ [5-11], в которых изучались комплексы йода $\mathrm{I}_{2}-\mathrm{I}_{2}$ в тетрахлорметане и $n$-гептане и в других растворителях [5-8], изучалось использование йода в качестве триплетного фотосенсибилизатора для получения син- глетного кислорода в углеводородном растворе при комнатной температуре [9] и в замороженной твердофазной аргоновой матрице [10]. В работе [11] отмечалось негативное влияние йода на генерацию синглетного кислорода с применением фуллерена $\mathrm{C}_{60}$ в качестве фотосенсибилизатора.

В последнее время в проводимых исследованиях большое внимание уделяется специфике галогеновой связи с растворителями (йода в частности) в плане органического синтеза и катализа [12-17], которая эффективно дополняет водородную связь. В этих работах показано, что молекулярный йод является отличным катализатором для многих органических превращений, но в то же время происхождение его каталитической активности, по мнению авторов работы [16], пока не до конца выяснено.

Поэтому исследование влияния йода на спектральные характеристики люминесценции синглетного кислорода в тетрахлорметане и в других растворителях, выполненное в настоящей работе, может оказаться полезным как в русле изучения специфики галогенной связи с растворителями, так и для дальнейшего понимания механизма образования структуры спектра люминесценции синглетного кислорода, индуцированного взаимодействием с растворителем $[18,19]$.

\section{Материалы и методика эксперимента}

При проведении исследований в качестве растворителей для фотосенсибилизаторов применялись тетрахлорметан $\mathrm{CCl}_{4}$, толуол, ацетон и этанол исходя из высокой растворимости в них молекулярного кислорода [20], а также достаточно большого времени жизни синглетного кислорода [21]. Чистота растворителей обеспечивалась двукратной перегонкой исходных образцов квалификации „ОСЧ“. Спектры поглощения растворов измерялись с помощью спектрофотометра UV-3600 (фирма Shimadzu, Japan). Образцы растворов объемом $1 \mathrm{ml}$ 

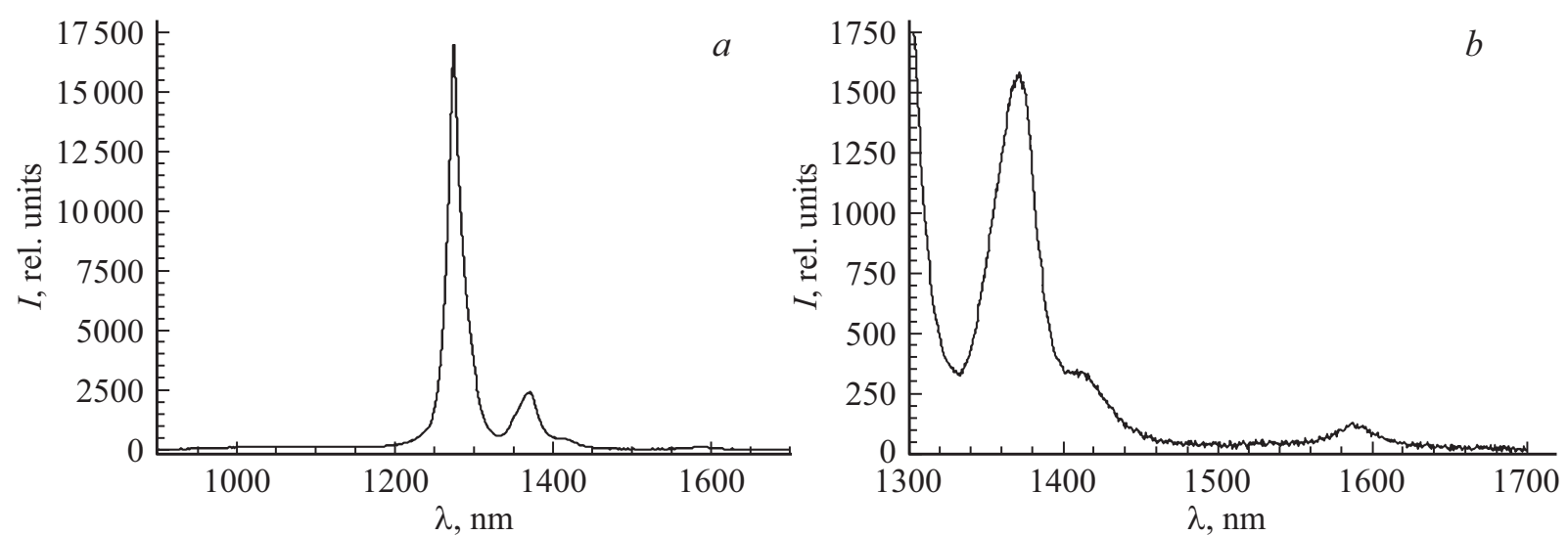

Рис. 1. Спектр люминесценции синглетного кислорода в растворе $\mathrm{BR}$ в $\mathrm{CCl}_{4}$ при возбуждении на $\lambda_{m}=525$ нм (плотность мощности $\left.0.6 \mathrm{~W} / \mathrm{cm}^{2}\right)$.

помещались в кварцевые оптические кюветы с длиной оптического пути $0.3 \mathrm{~cm}$. Степень чистоты используемых образцов фотосенсибилизаторов $99.96 \%$.

Для оптического возбуждения фотосенсибилизаторов использовались светодиодные матрицы $(2.3 \times 2.3 \mathrm{~cm})$ серии HPR40E (подводимая электрическая мощность $100 \mathrm{~W}$ ) с непрерывным излучением на длинах волн $\lambda_{m}=370,405,465,525$ и $625 \mathrm{~nm} \mathrm{с} \Delta \lambda_{0.5}=20 \mathrm{~nm}$ для всех матриц. Плотность мощности светодиодного излучения используемых матриц находится в диапазоне от $0.35 \mathrm{~W} / \mathrm{cm}^{2}\left(\lambda_{m}=370 \mathrm{~nm}\right)$ до $1.0 \mathrm{~W} / \mathrm{cm}^{2}\left(\lambda_{m}=625 \mathrm{~nm}\right)$. Измерение мощности излучения светодиодных источников осуществлялось измерителем мощности излучения Coherent-Molectron PS-10.

Основным методом при исследовании эффективности генерации синглетного кислорода для всех образцов, как и прежде [1], был метод регистрации люминесценции синглетного кислорода в ИК области спектра в районе перехода ${ }^{1} \Delta_{g} \rightarrow{ }^{3} \Sigma_{g}$ с применением ИК спектрометра SDH-IV с приемной InGaAs-линейкой фирмы Hamamatsu (Япония), выпускаемого фирмой „Солар Лазерные системы“ (Беларусь). Спектральный диапазон прибора от 868 до $1700 \mathrm{~nm}$. Предел спектрального разрешения прибора в диапазоне $1065-1330 \mathrm{~nm}$ не превышает $1.3 \mathrm{~nm}$. Применявшиеся схемы эксперимента со светодиодной оптической накачкой для исследуемых образцов представлены в [1].

\section{Результаты эксперимента и их обсуждение}

Характерный профиль спектра люминесценции синглетного кислорода в ИК диапазоне, наблюдаемый из раствора бенгальского розового (BR) в $\mathrm{CCl}_{4}$, представлен в общем виде на рис. 1, $a$ и отдельно для более слабых максимумов на рис. $1, b$. Спектральный профиль с $\lambda_{m}=1372 \mathrm{~nm}$ на этом рисунке заметно выделяется по интенсивности по сравнению с максимумами на $\lambda_{m}=1415$ и $1588 \mathrm{~nm}$. Но это только частный случай.
В свежеприготовленном растворе $\mathrm{BR}$ в $\mathrm{CCl}_{4}$ этого максимума нет совсем. Он появляется, постепенно увеличиваясь по амплитуде, на определенном временном интервале. Процесс его роста иллюстрируется на рис. 2. Кстати, подобный факт для растворителя $\mathrm{C}_{2} \mathrm{~F}_{4} \mathrm{Br}_{2}$ отмечался и в работе [2], который авторы этой работы связали с постепенным химическим процессом, происходящим в исследуемом растворе.

Очевидно, что в данном случае в растворе также происходит определенный химический процесс, который приводит к постепенному росту интенсивности сателлита, индуцированного колебаниями $\mathrm{C}-\mathrm{I}-$-вязи по аналогии с работой [2]. Этот химический процесс, вероятнее всего, связан с взаимодействием растворителя с красителем с замещением хлора йодом в молекуле $\mathrm{CCl}_{4}$. При этом, однако, в растворах красителя бенгальского розового в ацетоне, этаноле и толуоле данный сателлит нами не наблюдался.

В свое время этому взаимодействию растворителя с присутствующим в растворе йодсодержащим веществом с образованием различных комплексов йода было уделено очень большое внимание [5-8], которое нашло свое продолжение в работах [12-17] в плане органического синтеза и катализа.

Чтобы убедиться, что в исследуемом растворе бенгальского розового в $\mathrm{CCl}_{4}$ происходит взаимодействие растворителя с йодом, содержащимся в составе красителя, было решено сделать небольшую добавку (2 mg в $25 \mathrm{ml}$ ) кристаллического йода в раствор фуллерена

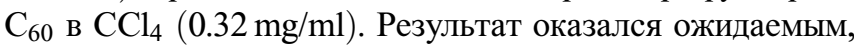
в спектре синглетного кислорода появился отчетливый сателлит с $\lambda_{m}=1372 \mathrm{~nm}$ при одновременном понижении интенсивности максимума на $\lambda_{m} \approx 1274 \mathrm{~nm}$ вследствие известного процесса передачи возбуждения от синглетного кислорода йоду $[22,23]$, который, как известно, лежит в основе работы кислород-йодного лазера [24,25].

В спектре люминесценции синглетного кислорода этот максимум на $\lambda_{m}=1372 \mathrm{~nm}$ появляется и при добавке кристаллического йода в исходный чистый 

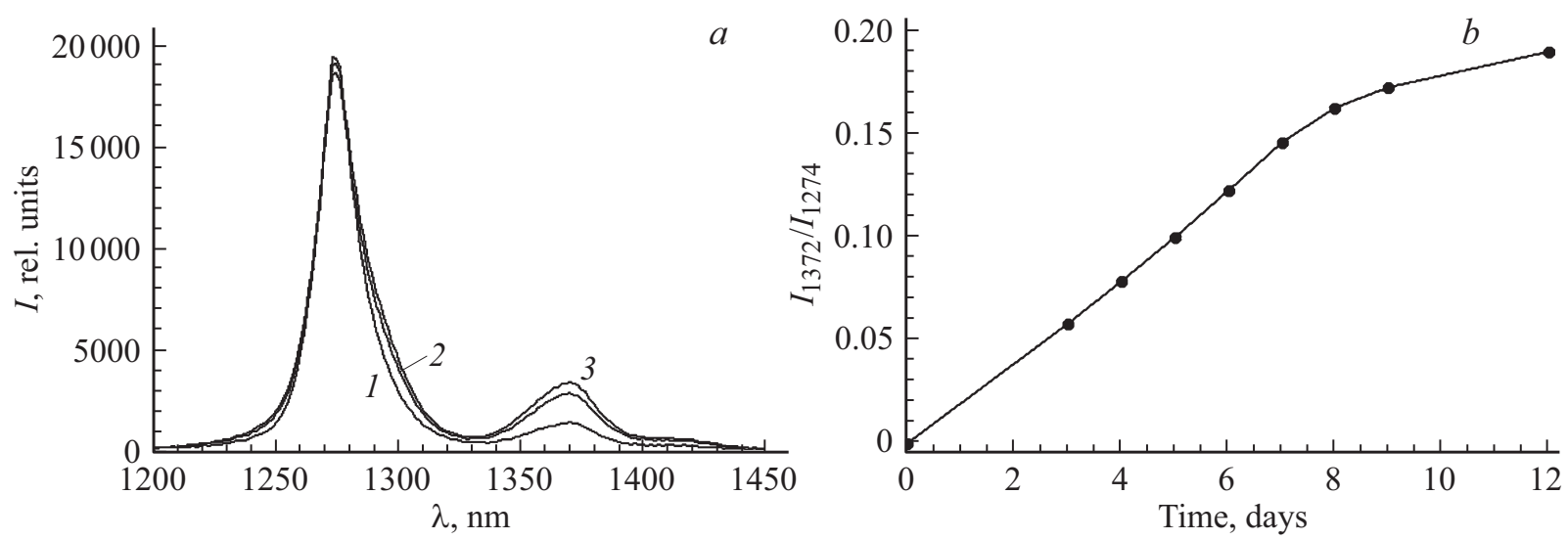

Рис. 2. Спектр люминесценции синглетного кислорода в растворе $\mathrm{BR}$ в $\mathrm{CCl}_{4}(a)$ на третий $(1)$, на пятый $(2)$ и на седьмой день (3) после растворения и временная зависимость отношения интенсивностей сателлита и $\lambda_{m}=1273.6 \mathrm{~nm}(b)$ при возбуждении на $\lambda_{m}=525 \mathrm{~nm}$ (плотность мощности $\left.0.6 \mathrm{~W} / \mathrm{cm}^{2}\right)$.
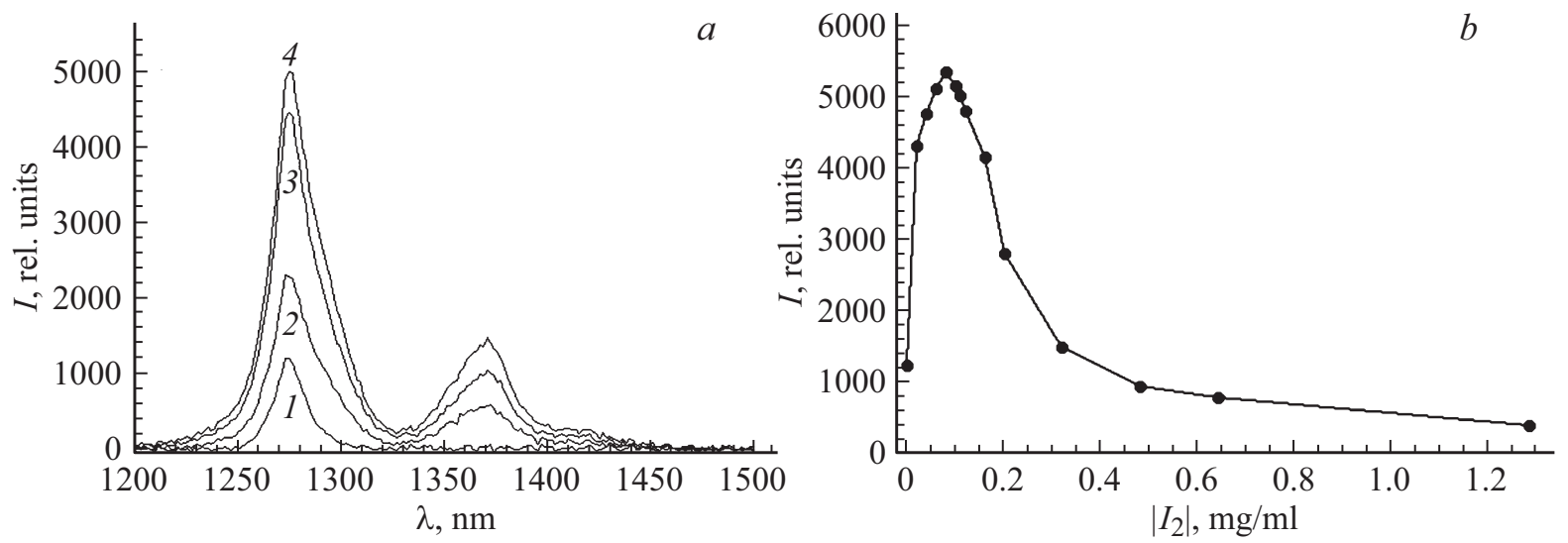

Рис. 3. Спектр люминесценции синглетного кислорода в растворе йода в $\mathrm{CCl}_{4}(a)$ при концентрациях йода в растворе $0(1)$, $0.005(2), 0.04(3)$ и $0.06 \mathrm{mg} / \mathrm{ml}$ (4) и зависимость эффективности генерации синглетного кислорода от концентрации йода в растворе $(b)$.

растворитель $\mathrm{CCl}_{4}$, в котором генерация синглетного кислорода, как известно, наблюдается и без наличия фотосенсибилизатора в растворе при прямом возбуждении молекулярного кислорода, растворенного в этом растворителе [26-28]. Как видно на рис. 3, $a$, при добавке йода в растворитель интенсивность генерации синглетного кислорода заметно возрастает по сравнению с той, которая была при прямом возбуждении молекулярного кислорода в отсутствие фотосенсибилизатора, что свидетельствует о том, что йод в данном растворе исполняет роль фотосенсибилизатора. Одновременно в спектре люминесценции появляется и максимум на $\lambda_{m}=1372 \mathrm{~nm}$. В данном случае этот максимум появляется сразу же после растворения йода в растворе с конечной интенсивностью без процесса постепенного роста, как это имело место в растворе $\mathrm{BR}$ в $\mathrm{CCl}_{4}$. Однако остается зависимость интенсивности этого максимума от концентрации йода в растворе, как и зависимость от этой концентрации эффективности генерации синглетного кислорода, как это видно на рис. $3, b$. Приведенные на рис. 3 результаты получены при возбуждении на $\lambda_{m}=525 \mathrm{~nm}$ (плотность мощности $\left.0.6 \mathrm{~W} / \mathrm{cm}^{2}\right)$.

Заметное уменьшение эффективности генерации синглетного кислорода с ростом концентрации йода в растворе объясняется активным действием уже отмеченного выше процесса передачи возбуждения от синглетного кислорода йоду $[22,23]$.

На рис. 3, $a$ можно отметить сдвиг максимума люминесценции синглетного кислорода для раствора йода в $\mathrm{CCl}_{4}$ по отношению к чистому растворителю $\mathrm{CCl}_{4}$, который составляет $1.6 \pm 0.2 \mathrm{~nm}$. Аддитивное действие растворителя и фотосенсибилизатора на сдвиг максимума спектра люминесценции синглетного кислорода отмечалось уже ранее $[1,26]$ для фуллерена $\mathrm{C}_{60} \quad \mathrm{~B}^{\mathrm{CCl}_{4}}$ и в толуоле, а здесь это явление наблюдается для йода в $\mathrm{CCl}_{4}$.

Тот факт, что йод в растворе в данном случае исполняет роль фотосенсибилизатора, подтверждается тесной корреляцией спектральной зависимости эффективности генерации синглетного кислорода в растворе 


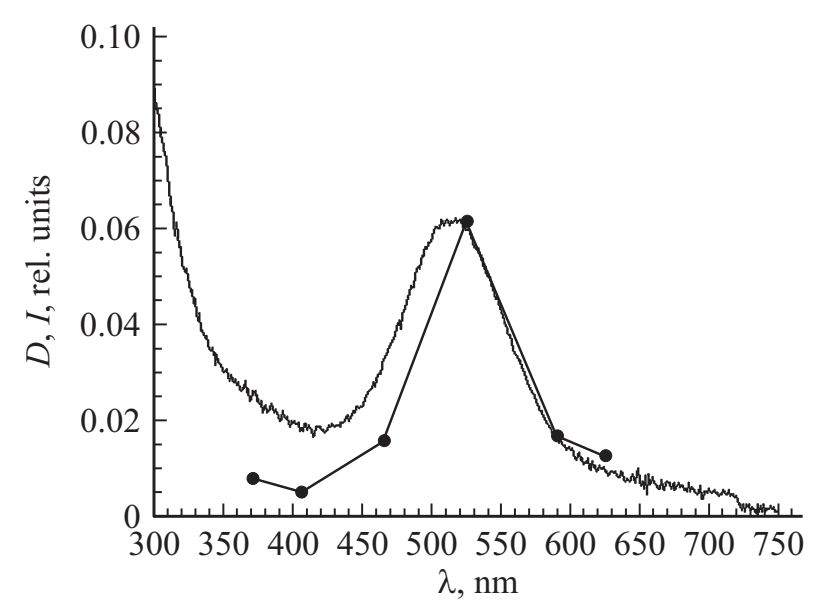

Pис. 4. Спектральный профиль поглощения раствора йода в $\mathrm{CCl}_{4}(1)$ и спектральная зависимость интенсивности люминесценции синглетного кислорода в этом растворе (2). Концентрация раствора $0.08 \mathrm{mg} / \mathrm{ml}$.

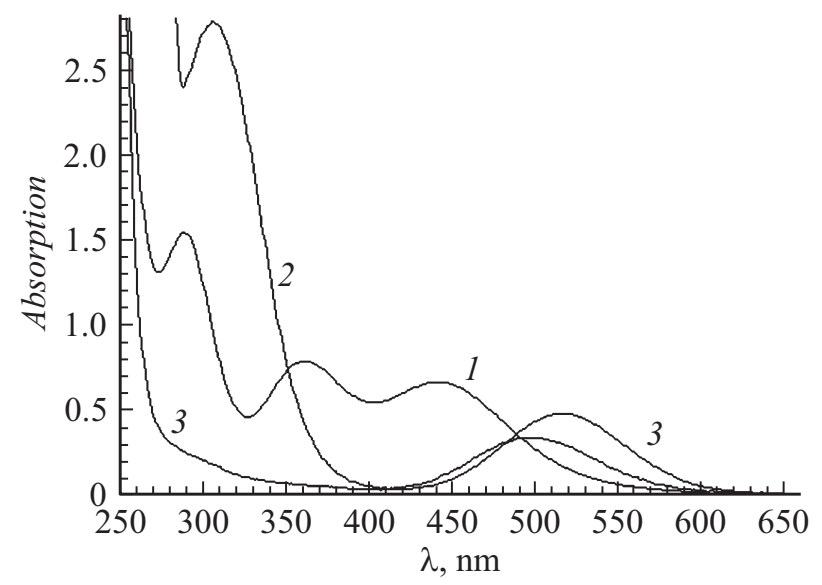

Рис. 5. Спектральные профили поглощения комплексов йода с растворителями: этанол (1), толуол (2) и тетрахлорметан (3).

йода $\mathrm{B} \mathrm{Cl}_{4}$ со спектральным профилем поглощения раствора йода в тетрахлорметане. Эти зависимости приведены на рис. 4. Для спектральной зависимости люминесценции представлены значения интенсивностей в максимуме спектрального профиля люминесценции, отнесенные к плотности мощности светового потока на выходе конкретной светодиодной матрицы. Более низкое левое крыло спектральной зависимости эффективности генерации синглетного кислорода в растворе йода в $\mathrm{CCl}_{4}$, по-видимому, объясняется влиянием наработки атомарного йода в этом спектральном диапазоне оптической накачки. А атомарный йод очень эффективно тушит возбужденное состояние ${ }^{1} \Delta_{g}$ молекулярного кислорода $[22,23]$ вследствие близости их энергетических уровней. Кстати, в отличие от работы [10], люминесценция из возбужденного состояния атомарного йода на переходе ${ }^{2} P_{1 / 2} \rightarrow{ }^{2} P_{3 / 2}$ из объема раствора в настоящей работе не наблюдалась.
Роль йода в качестве фотосенсибилизатора в других растворителях (ацетон, этанол, толуол) тоже была замечена, однако при значительно меньшей эффективности генерации синглетного кислорода вследствие более низкого значения времени жизни синглетного кислорода в этих растворителях [21]. Не было практически и сателлита на $\lambda_{m}=1372 \mathrm{~nm}$ в спектре люминесценции синглетного кислорода из объема растворов йода в этих растворителях, или, точнее, его сложно было заметить вследствие низкой эффективности генерации синглетного кислорода даже на основной линии с $\lambda_{m}=1274 \mathrm{~nm}$ по сравнению с раствором йода в $\mathrm{CCl}_{4}$.

По-видимому, следует еще раз отметить существенное различие в спектрах поглощения растворов йода в различных растворителях (рис. 5), наблюдаемое вследствие образования комплексов йода с растворителями, что уже многократно отмечалось ранее [29-31]. В этих комплекcax йод выступает в качестве акцептора, а молекулы растворителя в качестве донора.

Поэтому те особенности, что наблюдаются в спектре люминесценции синглетного кислорода из раствора йода в тетрахлорметане, не должны в обязательном порядке наблюдаться из раствора йода в других растворителях вследствие различной специфики комплексов йода в разных растворителях.

\section{Заключение}

В результате выполненного исследования влияния молекулярного йода на спектральные свойства люминесценции синглетного кислорода, наблюдаемого с применением красителя бенгальского розового и йода в качестве фотосенсибилизаторов, показано, что применение этого красителя и молекулярного йода для генерации синглетного кислорода демонстрирует все основные закономерности, которые были получены с другими фотосенсибилизаторами. Кроме того, показано, что формирование сателлита на $\lambda_{m}=1372 \mathrm{~nm}$, индуцированного колебаниями С-I-связи, наблюдается только в тетрахлорметане, и оно не было замечено в других исследованных растворителях.

Не наблюдалась и люминесценция из возбужденного состояния атомарного йода на переходе ${ }^{2} P_{1 / 2} \rightarrow{ }^{2} P_{3 / 2}$ из объема раствора в $\mathrm{CCl}_{4}$, которая отчетливо регистрировалась в работе [10] в замороженной твердофазной аргоновой матрице.

Несмотря на относительно узкий диапазон проведенных исследований и не очень большой объем полученных результатов, эти результаты все же могут оказаться в какой-то мере полезными для более качественного понимания механизма образования структуры спектра люминесценции синглетного кислорода, индуцированного взаимодействием с внешним окружением, и, в частности, с растворителем и йодсодержащими фотосенсибилизаторами. 
В заключение авторы считают своим приятным долгом отметить, что представленные исследования явились прямым продолжением инициированных А.А. Красновским мл. исследований по регистрации стоксовых компонент в спектре люминесценции синглетного кислорода, вследствие чего выражают ему свою признательность и благодарность.

Представленная работа выполнена при поддержке Российского фонда фундаментальных исследований (грант РФФИ № 14-02-00851a).

\section{Список литературы}

[1] Киселев В.М., Багров И.В. // Опт. и спектр. 2017. Т. 123. № 4. C. 125.

[2] Chou P.T., Khan A.U. // Chem. Phys. Lett. 1984. V. 103. N 4. P. 281.

[3] Nissen M.K., Wilson S.M., Thewalt M.L.W. // Phys. Rev. Lett. 1992. V. 69(16). P. 2423.

[4] Mohan Jag. Organic Spectroscopy: Principles and Application. Alpha Science International, Ltd; 2nd edition. 2004.

[5] De Maine P.A.D. // J. Chem. Phys. 1956. V. 24. P. 1091; Ibid. 1957. V. 26. P. 1192.

[6] Keefer R.M., Allen T.L. // J. Chem. Phys. 1956. V. 25. P. 1059.

[7] Strong R.L., Rand S.J., Britt J.A. // J. Am. Chem. Soc. 1960. V. 82(19). P. 5053.

[8] Bühler R.E., Ebert M. // Nature. 1967. V. 214. P. 1220.

[9] Olmsted III J., Karal G. // J. Am. Chem. Soc. 1972. V. 94(10). P. 3305.

[10] Bühling R., Becker A.C., Minaev B.F., Seranski K., Schurath U. // Chem. Phys. 1990. V. 142. P. 445.

[11] Багров И.В., Белоусова И.М., Ермаков А.В., Киселев В.М. u др. // Опт. и спектр. 2009. Т. 106. № 4. С. 570.

[12] Robertson C.C., Perutz R.N., Brammer L., Hunter C.A. // Chem. Sci. 2014. V. 5. P. 4179.

[13] Xue Pang, Wei Jun Jin. // New J. Chem. 2015. V. 39. P. 5477.

[14] Yusubov M.S., Zhdankin V.V. // Resource-Efficient Technologies. 2015. V. 1. P. 49.

[15] Bulfield D., Huber S.M. // Chemistry A European J. 2016. V. 22. N 41. P. 14434.

[16] Breugst M., Detmar E., von der Heiden D. // ACS Catal. 2016. V. 6(5). P. 3203.

[17] Benz S., López-Andarias J., Mareda J., Sakai N., Matile S. // Angewandte Chem. 2017. V. 56. N 3. P. 812.

[18] Minaev B.F. // J. Molecular Structure (Theochem). 1989. V. 183. P. 207.

[19] Minaev B.F. Lunella S., Kobzev G.I. // J. Molecular Structure (Theochem). 1993. V. 284. P. 1-9.

[20] Разумовский С.Д. Кислород - элементарные формы и свойства. М.: Химия, 1979.

[21] Schweitzer C., Schmidt R. // Chem. Rev. 2003. V. 103(5). P. 1685.

[22] Derwent R.G., Thrush B.A. // J. Chem. Soc., Faraday Trans. 2: Molecular and Chem. Phys. 1972. V. 68. P. 720.

[23] Derwent R.G., Thrush B.A. // Farad. Discuss. Chem. Soc. 1972. V. 53. P. 162.

[24] McDermott W.E., Pchelkin N.R., Benard D.J., Bousek R.R. // Appl. Phys. Lett. 1978. V. 32. P. 469.
[25] Benard D.J., McDermott W.C., Pchelkin N.R., Bousek R.R. // Appl. Phys. Lett. 1979. V. 34. P. 40.

[26] Багров И.В., Белоусова И.М., Киселев В.М., Кисляков И.М., Соснов Е.Н. // Опт. и спектр. 2012. Т. 113. № 1. C. 59.

[27] Багров И.В., Киселев В.М., Кисляков И.М., Соснов Е.Н. // Опт. и спектр. 2014. Т. 116. № 4. С. 609.

[28] Киселев В.М., Кисляков И.М., Багров И.В. // Опт. и спектр. 2016. Т. 120. № 6. С. 916.

[29] Walker II L.A., Pullen S., Donovan B., Sension R.J. // Chem. Phys. Lett. 1995. V. 242. N 1-2. P. 177.

[30] Liu Z.-B., Tian J.-G., Zang W.-P. et al. // Optics Lett. 2004. V. 29. N 10. P. 1099.

[31] Refat M.S., El-Didamony A.M., Grabchev I. // Spectrochim. Acta. Part A: Molecular and Biomolecular Spectroscopy. 2007. V. 67. N 1. P. 58. 